This item was submitted to Loughborough's Research Repository by the author.

Items in Figshare are protected by copyright, with all rights reserved, unless otherwise indicated.

\title{
Three-dimensional multi-phase model of PEM fuel cell coupled with improved agglomerate sub-model of catalyst layer
}

PLEASE CITE THE PUBLISHED VERSION

https://doi.org/10.1016/j.enconman.2019.112051

PUBLISHER

Elsevier BV

VERSION

AM (Accepted Manuscript)

\section{PUBLISHER STATEMENT}

This paper was accepted for publication in the journal Energy Conversion and Management and the definitive published version is available at https://doi.org/10.1016/j.enconman.2019.112051

LICENCE

CC BY-NC-ND 4.0

\section{REPOSITORY RECORD}

Xie, Biao, Guobin Zhang, Jin Xuan, and Kui Jiao. 2019. "Three-dimensional Multi-phase Model of PEM Fuel Cell Coupled with Improved Agglomerate Sub-model of Catalyst Layer”. figshare.

https://hdl.handle.net/2134/10856711.v1. 
1 Three-dimensional multi-phase model of PEM fuel cell coupled with improved agglomerate sub-model of catalyst layer

Biao Xie ${ }^{1}$, Guobin Zhang ${ }^{1}$, Jin Xuan ${ }^{2}$, Kui Jiao ${ }^{1 *}$

\section{Abstract}

An improved agglomerate sub-model of catalyst layer (CL) involving actual

11 agglomerate size and oxygen local transport characteristics is developed and incorporated into a three-dimensional (3D) multi-phase model of proton exchange

13 membrane (PEM) fuel cell. This makes it capable to consider the effect of Platinum

$14(\mathrm{Pt})$ loading on oxygen transport and fuel cell performance more accurately. Oxygen

15 local transport resistance near the catalyst surface is divided into three parts caused

16 by liquid water blockage, ionomer coverage and Pt/carbon agglomeration,

17 respectively. The resistances caused by ionomer coverage and $\mathrm{Pt} /$ carbon

18 agglomeration are two major sources of oxygen local transport resistance. They have

19 opposite variation trends as Pt loading changes. However, the ionomer resistance

20 increases dramatically when Pt loading is lower than $0.1 \mathrm{mg} \mathrm{cm}^{-2}$ because of the

21 much harder transport process through a relatively heavier ionomer coating. The

22 simulation results agree with the experimental data reasonably under different 
23 cathode Pt loadings (from 0.3 to $0.025 \mathrm{mg} \mathrm{cm}^{-2}$ ), for both polarization curves and

24 local transport resistance. In addition, a transport dominance parameter is defined to

25 judge whether the concentration loss predominates the electrochemical reaction. A

26 value greater than $10 \%$ can be seen as a symbol of local oxygen starvation. Using

27 this model, fine channel geometry with extremely small channel and rib widths is

28 investigated, and the highest net output power in this study is corresponding to 0.2

29 and $0.6 \mathrm{~mm}$ for channel (rib) width and height.

30

\section{Keywords}

32 PEM fuel cell; Catalyst layer; Agglomerate model; Pt loading; Oxygen transport;

33 Fine channel geometry

34

35 Nomenclature

$\begin{array}{ll}A & \text { specific surface area }\left(\mathrm{m}^{-1}\right) \\ A_{\text {act }} & \text { active area }\left(\mathrm{m}^{2}\right) \\ a & \text { water activity } \\ a_{\mathrm{ECSA}} & \text { electrochemically active surface area }\left(\mathrm{m}^{2} \mathrm{~g}^{-1}\right) \\ C_{\mathrm{i}} & \text { gas molar concentration }\left(\mathrm{mol} \mathrm{m}^{-3}\right) \\ C_{\mathrm{p}} & \text { specific heat capacity }\left(\mathrm{J} \mathrm{mol}^{-1} \mathrm{~K}^{-1}\right) \\ D_{\mathrm{i}} & \text { gas diffusivity }\left(\mathrm{m}^{2} \mathrm{~s}^{-1}\right)\end{array}$




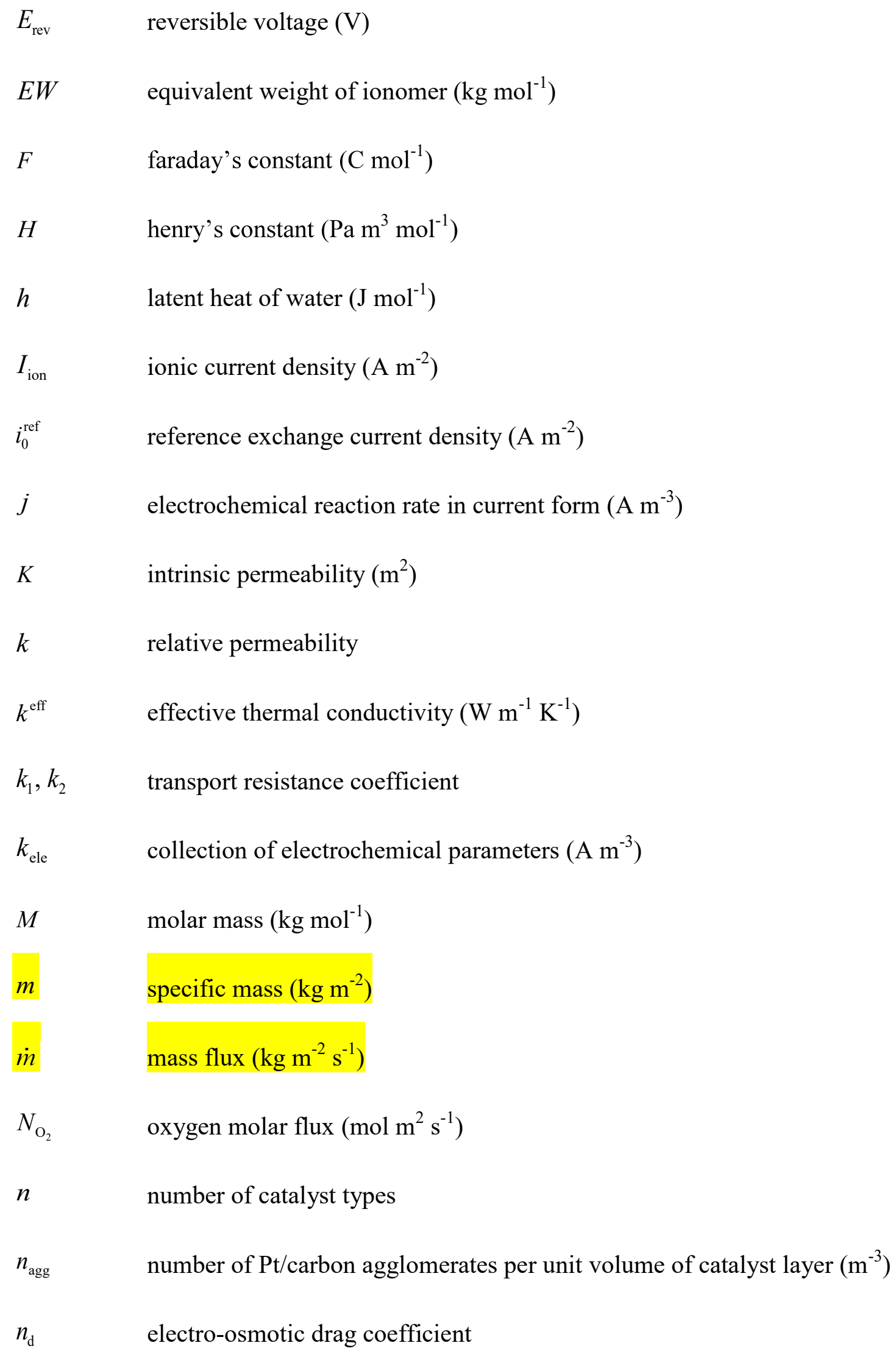




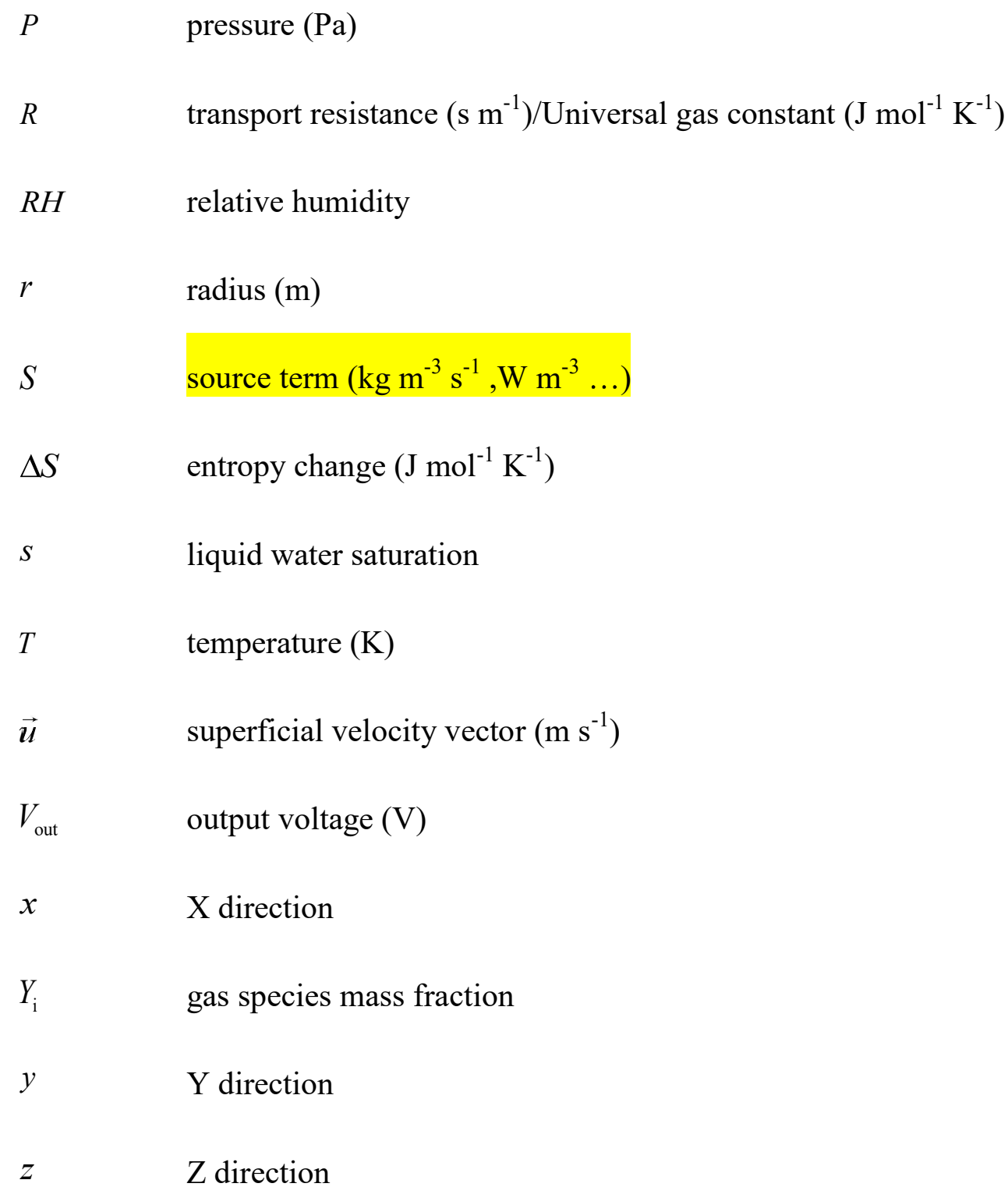




\begin{tabular}{|c|c|}
\hline$\zeta_{\mathrm{pt} / \mathrm{c}}$ & platinum weight percentage of $\mathrm{Pt} /$ carbon catalyst \\
\hline$\zeta_{\mathrm{im} / \mathrm{c}}$ & mass ratio of ionomer to carbon \\
\hline$\eta$ & overpotential (V) \\
\hline$\theta$ & correction coefficient \\
\hline$l$ & transport dominance \\
\hline$\kappa_{\text {ele }}$ & electronic conductivity $\left(\mathrm{S} \mathrm{m}^{-1}\right)$ \\
\hline$\kappa_{\text {ion }}$ & ionic conductivity $\left(\mathrm{S} \mathrm{m}^{-1}\right)$ \\
\hline$\lambda$ & membrane water content \\
\hline$\mu$ & dynamic viscosity $\left(\mathrm{kg} \mathrm{m}^{-1} \mathrm{~s}^{-1}\right)$ \\
\hline$\xi$ & stoichiometric ratio \\
\hline$\rho$ & density $\left(\mathrm{kg} \mathrm{m}^{-3}\right)$ \\
\hline$\varphi_{\text {ele }}$ & electronic potential (V) \\
\hline$\varphi_{\text {ion }}$ & ionic potential (V) \\
\hline$\chi$ & mass fraction of different catalyst type \\
\hline$\omega$ & energy parameter $\left(\mathrm{J} \mathrm{mol}^{-1}\right)$ \\
\hline
\end{tabular}

39 Subscripts and superscripts

$0 \quad$ standard state

ACL anode catalyst layer

a anode 


\begin{tabular}{|c|c|}
\hline act & active \\
\hline agg & agglomerate \\
\hline ave & average \\
\hline BP & bipolar plate \\
\hline $\mathrm{CL}$ & catalyst layer \\
\hline CCL & cathode catalyst layer \\
\hline $\mathrm{c}$ & cathode/carbon support \\
\hline diffu & diffusion \\
\hline disso & dissolution \\
\hline ECSA & electrochemically active surface area \\
\hline eff & effective \\
\hline ele & electronic \\
\hline eq & equivalent/equilibrium \\
\hline GDL & gas diffusion layer \\
\hline $\mathrm{g}$ & gas state/gas mixture \\
\hline $\mathrm{H}$ & Henry's law correction \\
\hline $\mathrm{H}_{2} \mathrm{O}$ & water vapor \\
\hline $\mathrm{i}$ & gas species or catalyst type \\
\hline im & ionomer \\
\hline $\mathrm{im} / \mathrm{c}$ & ionomer/carbon \\
\hline
\end{tabular}




\begin{tabular}{|c|c|}
\hline in & inlet \\
\hline ion & ionic \\
\hline $\mathrm{Kn}$ & Knudsen diffusion \\
\hline local & local transport \\
\hline lw & liquid water \\
\hline $1-\mathrm{v}$ & liquid water to water vapor \\
\hline MEM & membrane \\
\hline MF & metal foam \\
\hline MPL & micro-porous layer \\
\hline $\mathrm{m}$ & mass \\
\hline $\mathrm{mw}$ & membrane water \\
\hline $\mathrm{O}_{2}$ & Oxygen \\
\hline out & output \\
\hline $\mathrm{pt}$ & platinum/near platinum surface \\
\hline $\mathrm{p}$ & pore \\
\hline $\mathrm{pt} / \mathrm{c}$ & platinum/carbon \\
\hline $\mathrm{pt} / \mathrm{im}$ & platinum-ionomer coverage-dependent \\
\hline $\mathrm{pt} / \mathrm{o}$ & platinum-oxide coverage-dependent \\
\hline ref & reference \\
\hline rev & reversible \\
\hline
\end{tabular}




$\begin{array}{ll}\text { sat } & \text { saturation } \\ \mathrm{T} & \text { temperature } \\ \mathrm{v} & \text { water vapor } \\ \mathrm{v}-\mathrm{m} & \text { water vapor to membrane water } \\ \mathrm{v}-1 & \text { water vapor to liquid water } \\ * & \text { correction }\end{array}$

\section{1. Introduction}

42 As one of the most promising energy conversion devices in the future, proton

43 exchange membrane (PEM) fuel cell has attracted much attention in recent years.

44 It's adequate for portable, stationary and especially transportation applications due to little road emissions, low operation temperature and high efficiency [1]. However,

46 key challenges still obstruct its large-scale commercialization, e.g. the high cost. The precious metal catalyst - - Platinum (Pt) used in catalyst layer (CL) mainly contributes to the price of membrane electrode assembly (MEA). According to the 2015 review of the U.S. Department of Energy (DOE), the Pt utilization needs to attain $0.125 \mathrm{~g} \mathrm{~kW}^{-1}$ in order to meet the market demand [2]. Therefore, it is of great

51 significance to reduce Pt loading appropriately without severely dampening the cell

52 performance. This requires deep understanding of physicochemical phenomena that

53 occur in PEM fuel cell catalyst layer. 
55 During the past decades, modeling or simulation has become a powerful tool to

56 investigate the multi-scale transport phenomena and electrochemical reactions inside

57 PEM fuel cell. For catalyst layer, it consists of catalyst (carbon supported Pt),

58 ionomer (Nafion) and void region, which conducts or transfers electron, proton and

59 mass (gas and liquid), respectively. Early CL models like interface model and

60 homogenous model $[3,4]$ regarded $C L$ as a boundary condition or specified the

61 volume fraction of different phase, which overestimated the fuel cell performance.

62 In fact, the cathode is prone to suffer great concentration loss especially under high

63 current density, due to the slow oxygen transport process. In order to consider the

64 difficulty of oxygen transport and structural details of CL, Ridge et al. [5] firstly

65 introduced the concept of agglomerate into CL modeling. In the agglomerate CL,

66 spherical agglomerates of $\mathrm{Pt} /$ carbon clumps coated by ionomer film distributes

67 randomly to form a porous structure. Siegel et al. [6] applied the agglomerate model

68 and predicted the polarization curve with more accuracy. They emphasized the close

69 connection between CL structure and fuel cell performance. Sun et al. [7] developed

70 a two-dimensional agglomerate model and studied the influence of structural

71 parameters. They mentioned that a lower but acceptable Pt loading could be better

72 than higher loading. Actually, lower catalyst loading may provide more void space

73 which is beneficial for gas transport. However, oxygen transport resistance can

74 increase dramatically when Pt loading decreases to a certain level. 
76 Using limiting current measurement, Nissan's research and development center reported higher oxygen transport resistance as Pt loading decreased [8]. The additional resistance was pressure independent and they assumed that it could originate from a thin ionomer film with low permeability. Greszler et al. [9] presented limiting current results of oxygen local transport resistance over a wider range of Pt loadings. The resistance increased greatly when Pt loading was lower than $0.1 \mathrm{mg} \mathrm{cm}^{-2}$ because of more oxygen flux through ionomer. And the magnitude was equivalent to the resistance created by $380 \mathrm{~nm}$ diameter agglomerates with $20 \mathrm{~nm}$ uniform ionomer coating, assuming bulk diffusion effect only. The geometry size agreed with parameters used in traditional agglomerate models [7, 10]. Nevertheless, it was not supported by microscopic observations, in which the agglomerate exaggerated geometry size. 
just fitting parameters in order to match the experimental data. Hao et al. [13] adopted two interfacial resistances and coupled them with bulk diffusion by assigning two coefficients at gas-ionomer interface and Pt-ionomer interface, respectively. They employed small-size homogeneous-distributed $\mathrm{Pt} /$ carbon particles in CL model and gained agreement with the experiments on both polarization curves and transport resistance. Owejan et al.'s [14] experimental work drew a conclusion that the resistance through the ionomer coating was a function of both Pt surface area and Pt particle dispersion. Chen et al. [15] carried out a pore-scale simulation using the lattice Boltzmann method and reconstructed ionomer-coated Pt/carbon particle. The relationship between oxygen local transport resistance and microscopic factors was discussed, including ionomer dissolution and Pt particle dispersion. They concluded that local transport characteristics should be considered when developing agglomerate model. Very recently, Sina et al. [16] conducted a direct measurement of relative gas diffusivity in CL through modified Loschmidt cell method. They also built up an agglomerate-formed CL model by specifying the arrangement of agglomerates which was validated with the measurement data. They emphasized the importance of pore size distribution in catalyst layer and suggested two major ranges. The secondary pores ( 200nm in diameter) among agglomerates mainly provides pathways for mass transport, in which bulk diffusion plays a major role. And for primary pores ( $\sim 20 \mathrm{~nm}$ in diameter) inside agglomerates, the Knudsen diffusion becomes dominant and adds difficulty to gas transport. Generally speaking, 
118 the oxygen local transport characteristics may vary remarkably under different Pt

119 loadings, which significantly affects the mass transport property of CL. This Pt

120 loading effect was hardly reflected in traditional agglomerate models because Pt

121 loading only changed the effective reaction area $[7,10]$. It's necessary to consider

122 more structural details including Pt loading effect so that the agglomerate model can

123 be more valid and reflect the influence of the CL microstructure more accurately.

125 Therefore, an improved agglomerate sub-model of CL is firstly developed

126 considering the actual geometry size of agglomerates in this study. At single

127 agglomerate scale, oxygen local transport resistance is clarified with three individual

128 parts caused by liquid water, thin ionomer film and $\mathrm{Pt} /$ carbon agglomeration,

129 respectively. The dissolution effect at gas-ionomer interface is coupled with

130 diffusion resistance through the ionomer film. The Pt particle dispersion on carbon

131 support as well as Knudsen diffusion in primary pores is also taken into account.

132 Consequently, the CL model is capable to reflect the influence of Pt loading change

133 more practically. By incorporating the improved agglomerate sub-model into a

134 three-dimensional (3D) multi-phase non-isothermal PEM fuel cell model, it is

135 carefully validated with experimental data under different cathode Pt loadings. To

136 the best of the authors' knowledge, only a few studies have considered detailed local

137 oxygen transport characteristics in CL when using 3D macroscopic PEM fuel cell

138 model. Furthermore, the effects of transport factors and electrochemical factors are 
140 dominance factor. Using the developed model, some optimized designs of fine

141 channel geometry aiming at reducing concentration loss of PEM fuel cell are 142 studied.

\section{2. Model development}

\subsection{Agglomerate sub-model of CL}

146 Fig. 1(a) shows the SEM image of CL [16], in which the primary and secondary

147 pores can be clearly seen. And transmission electron microscope (TEM) image of

148 CL sample in Fig. 1(b) gives a deeper view of primary pore and Pt particle

149 dispersion on carbon support. Based on the real CL structure, the schematic of single

150 agglomerate is displayed in Fig. 1(c). The primary pore inside the high-surface-area

151 carbon support is treated as a cylindrical hole for calculation simplicity. In fact, $\mathrm{Pt}$

152 particles are also likely to migrate into primary pores along with agglomeration and

153 coalescence [17], besides depositing onto outer surface of carbon support.

155 As seen in Fig. 1 (c), the oxygen local transport resistance in this agglomerate 156 sub-model is divided into three parts:

157 1. The resistance caused by liquid water in secondary pores $\left(R_{\mathrm{lw}}, \mathrm{s} \mathrm{m}^{-1}\right)$, which can 158 be expressed by Fick's diffusion: 


$$
R_{\mathrm{lw}}=\frac{\delta_{\mathrm{lw}}^{\mathrm{eq}}}{D_{\mathrm{O}_{2}, \mathrm{lw}}}
$$

160 where $\delta_{\mathrm{lw}}^{\mathrm{eq}}(\mathrm{m})$ is the equivalent water film thickness and $D_{\mathrm{O}_{2}, \mathrm{lw}}\left(\mathrm{m}^{2} \mathrm{~s}^{-1}\right)$ the oxygen

161 diffusivity in water. Actually, liquid water only occupies part of void space and can

162 be removed by capillary effect, which means that a continuous water film on

163 ionomer surface may not exist, therefore, the equivalent film thickness is assumed:

$$
\delta_{\mathrm{lw}}^{\mathrm{eq}}=\frac{s \varepsilon_{\mathrm{CL}}}{A_{\mathrm{im}}}
$$

165 where $s, \varepsilon_{\mathrm{CL}}$ and $A_{\mathrm{im}}\left(\mathrm{m}^{-1}\right)$ are the liquid water saturation, porosity of $\mathrm{CL}$ and

166 specific surface area of ionomer film, respectively.

167 2. The resistance caused by thin ionomer film $\left(R_{\mathrm{im}}, \mathrm{s} \mathrm{m}^{-1}\right)$, which consists of

168 dissolution part and diffusion part:

$$
R_{\mathrm{im}}=R_{\mathrm{im}, \mathrm{disso}}+R_{\mathrm{im}, \mathrm{diffu}}
$$

171 where $\delta_{\text {im }}(\mathrm{m})$ is the thickness of thin ionomer film and $D_{\mathrm{O}_{2}, \mathrm{~m}}\left(\mathrm{~m}^{2} \mathrm{~s}^{-1}\right)$ the oxygen

172 diffusivity in ionomer. The dissolution resistance is usually coupled with the

173 diffusion resistance through a coefficient. In Hao et al.'s [13] work, the specific

174 surface area ratio of ionomer to $\mathrm{Pt}\left(A_{\mathrm{im}} / A_{\mathrm{pt}}\right)$ was adopted to modify the diffusion in

175 ionomer film. It can be applied to relate these two resistances so that the dissolution

176 effect is considered:

$$
R_{\text {im,disso }}=k_{1} \frac{A_{\text {im }}}{A_{\mathrm{pt}}} R_{\text {im,diffu }}
$$


178

179 3. The resistance caused by $\mathrm{Pt} /$ carbon agglomeration $\left(R_{\mathrm{pt}}, \mathrm{s} \mathrm{m}^{-1}\right)$. In primary pores,

where $k_{1}$ is set as a undetermined coefficient.

180 transport resistance could be a complicated mixing hindrance. Besides liquid water and ionomer, the Knudsen diffusion should be considered as earlier mentioned:

$$
R_{\mathrm{pt}}=\frac{\delta_{\mathrm{pt}}^{\mathrm{eq}}}{D_{\mathrm{O}_{2}, \mathrm{pt}}^{\mathrm{eq}}}
$$

where $D_{\mathrm{O}_{2}, \mathrm{pt}}^{\mathrm{eq}}\left(\mathrm{m}^{2} \mathrm{~s}^{-1}\right)$ is the equivalent oxygen diffusion coefficient in primary pores,

187 constant, $T(\mathrm{~K})$ the local temperature and $M\left(\mathrm{~kg} \mathrm{~mol}^{-1}\right)$ the molecular weight of oxygen. And the equivalent diffusion length $\left(\delta_{\mathrm{pt}}^{\mathrm{eq}}, \mathrm{m}\right)$ is simply assumed to be half of carbon support radius $\left(r_{\mathrm{c}}, \mathrm{m}\right)$. The pore radius $\left(r_{\mathrm{p}}, \mathrm{m}\right)$ is calculated based on the assumption that all the pores are placed together with the cylindrical shape: $D_{\mathrm{O}_{2}, \mathrm{Kn}}\left(\mathrm{m}^{2} \mathrm{~s}^{-1}\right)$ the Knudsen diffusion coefficient, $R\left(\mathrm{~J} \mathrm{~mol}^{-1} \mathrm{~K}^{-1}\right)$ the universal gas

192 where $\varepsilon_{\mathrm{c}}$ is the porosity of carbon support. It should be noted that this resistance is 193 only valid for $\mathrm{Pt}$ particles that fall into primary pores so that a correction is 194 necessary:

$$
r_{\mathrm{p}}=\sqrt{\frac{4 \varepsilon_{\mathrm{c}}}{3}} r_{\mathrm{c}}
$$

$$
R_{\mathrm{pt}}^{*}=k_{2} R_{\mathrm{pt}}
$$

196 where $k_{2}$ is correction coefficient which should be associated with the Pt loading, 
197 or more exactly, with the $\mathrm{Pt}$ weight percentage of $\mathrm{Pt} /$ carbon catalyst $(\mathrm{Pt} / \mathrm{C}$

198 percentage). As mentioned before, the Pt particle dispersion is also a significant

199 factor affecting oxygen transport and consumption. Pt particles are prone to get

200 concentrated at high $\mathrm{Pt} / \mathrm{C}$ percentage [14] and the deposition into primary pores may

201 increase. On the contrary, $\mathrm{Pt}$ particles are more dispersed at low $\mathrm{Pt} / \mathrm{C}$ percentage.

202 Herein, the correction coefficient is assumed to equal an average $\mathrm{Pt} / \mathrm{C}$ percentage,

203 which has the same value as actual $\mathrm{Pt} / \mathrm{C}$ percentage when only one kind of $\mathrm{Pt} / \mathrm{carbon}$

204 catalyst is used.

$$
k_{2}=\zeta_{\mathrm{pt} / \mathrm{c}}^{\mathrm{ave}}=\sum_{i=1}^{n} \frac{\zeta_{\mathrm{pt} / \mathrm{i}, \mathrm{i}} \chi_{\mathrm{i}}}{\sum_{j=1}^{n} \zeta_{\mathrm{pt} / \mathrm{c}, \mathrm{j}} \chi_{\mathrm{j}}} \zeta_{\mathrm{pt} / \mathrm{c}, \mathrm{i}}
$$

206 where $\zeta_{\mathrm{ptc}, \mathrm{i}}, \quad \chi_{\mathrm{i}}$ and $n$ are the $\mathrm{Pt} / \mathrm{C}$ percentage, mass fraction of different catalyst

207 type and the number of types, respectively.

209 In total, the total oxygen local transport resistance $\left(R_{\text {local }}, \mathrm{s} \mathrm{m}^{-1}\right)$ from secondary

210 pores to $\mathrm{Pt}$ surface is:

$$
R_{\mathrm{local}}=R_{\mathrm{lw}}+R_{\mathrm{im}}+R_{\mathrm{pt}}^{*}=R_{\mathrm{lw}}+\left(k_{1} \frac{A_{\mathrm{im}}}{A_{\mathrm{pt}}}+1\right) R_{\mathrm{im}, \mathrm{diffu}}+k_{2} R_{\mathrm{pt}}
$$

212 Overall, oxygen local transport resistance in Eq. (12) can be seen as a function of Pt

213 surface area and Pt particle dispersion just as Owejan concluded [14]. In addition,

214 Henry's law is used to describe the concentration drop at gas-ionomer interface: 


$$
C_{\mathrm{O}_{2}}^{\mathrm{H}}=\frac{C_{\mathrm{O}_{2}}^{\mathrm{g}} R T}{H_{\mathrm{O}_{2}}}
$$

216 where $C_{\mathrm{O}_{2}}^{\mathrm{H}}\left(\mathrm{mol} \mathrm{m} \mathrm{m}^{-3}\right)$ represents the oxygen concentration at the gas-ionomer

217 interface and $H_{\mathrm{O}_{2}}\left(\mathrm{~Pa} \mathrm{~m}^{3} \mathrm{~mol}^{-1}\right)$ is the Henry's constant of oxygen in ionomer. Then

218 the oxygen flux $\left(N_{\mathrm{O}_{2}}\right.$, mol m $\left.\mathrm{m}^{-2} \mathrm{~s}^{-1}\right)$ can be obtained:

$$
N_{\mathrm{O}_{2}}=\frac{C_{\mathrm{O}_{2}}^{\mathrm{H}}-C_{\mathrm{O}_{2}}^{\mathrm{pt}}}{R_{\text {local }}}
$$

220 The oxygen that arrives at Pt surface (effective) is assumed to be consumed by

221 electrochemical reaction immediately:

$$
N_{\mathrm{O}_{2}} A_{\text {im }}=\frac{j_{\mathrm{c}}}{4 F}
$$

223 where $j_{\mathrm{c}}\left(\mathrm{A} \mathrm{m}^{-3}\right)$ is the reaction rate and $F\left(\mathrm{C} \mathrm{mol}^{-1}\right)$ the Faraday constant. Number

224 of agglomerates per unit volume of CL can be calculated using the compositional

225 and structural parameters:

$$
n_{\mathrm{agg}}=\frac{m_{\mathrm{pt}}}{\delta_{\mathrm{CL}}}\left[\frac{1}{\rho_{\mathrm{pt}}}+\left(\frac{1}{\zeta_{\mathrm{pt} / \mathrm{c}}}-1\right) \frac{1}{\rho_{\mathrm{c}}}\right] \frac{3}{4 \pi r_{\mathrm{c}}^{3}}
$$

227 where $m_{\mathrm{pt}}\left(\mathrm{mg} \mathrm{cm}^{-2}\right)$ is the Pt loading, $\delta_{\mathrm{CL}}(\mathrm{m})$ the CL thickness and $\rho_{\mathrm{pt}}, \rho_{\mathrm{c}}\left(\mathrm{kg} \mathrm{m}^{-3}\right)$

228 the density of platinum and carbon, respectively. And the ionomer film thickness is

229 calculated using the mass ratio of ionomer to carbon (I/C ratio):

$$
\delta_{\mathrm{im}}=\frac{\zeta_{\mathrm{im} / \mathrm{c}} m_{\mathrm{pt}}}{\rho_{\mathrm{im}} \delta_{\mathrm{CL}} n_{\mathrm{agg}} 4 \pi r_{\mathrm{c}}^{2}}\left(\frac{1}{\zeta_{\mathrm{pt} / \mathrm{c}}}-1\right)
$$

231 where $\zeta_{\mathrm{im} / \mathrm{c}}$ is the $\mathrm{I} / \mathrm{C}$ ratio and $\rho_{\mathrm{im}}\left(\mathrm{kg} \mathrm{m}^{-3}\right)$ the dry ionomer density. Moreover,

232 the specific surface area of ionomer and Pt can be obtained by: 


$$
A_{\text {im }}=4 \pi\left(r_{\mathrm{c}}+\delta_{\text {im }}\right)^{2} n_{\text {agg }}
$$

$$
A_{\mathrm{pt}}=\frac{m_{\mathrm{pt}} a_{\mathrm{ECSA}}}{\delta_{\mathrm{CL}}}
$$

235 where $a_{\mathrm{ECSA}}\left(\mathrm{m}^{2} \mathrm{~g}^{-1}\right)$ is the electrochemically active surface area (ECSA).

237 In addition, the volume fractions of three phase in CL are given as below:

238 Solid phase (carbon and Pt):

$$
\varepsilon_{\mathrm{pt} / \mathrm{c}}=\frac{m_{\mathrm{pt}}}{\delta_{\mathrm{CL}}}\left[\frac{1}{\rho_{\mathrm{pt}}}+\left(\frac{1}{\zeta_{\mathrm{p} t / \mathrm{c}}}-1\right) \frac{1}{\rho_{c}}\right]
$$

Electrolyte phase (ionomer or Nafion):

$$
\varepsilon_{\mathrm{im}}=\frac{\zeta_{\mathrm{im} / \mathrm{c}} m_{\mathrm{pt}}}{\delta_{\mathrm{CL}} \rho_{\mathrm{im}}}\left(\frac{1}{\zeta_{\mathrm{pt} / \mathrm{c}}}-1\right)\left(1+\frac{M_{\mathrm{lw}} \rho_{\mathrm{im}}}{\rho_{\mathrm{lw}} E W} \lambda\right)
$$

242 Pore phase (porosity):

$$
\varepsilon_{\mathrm{CL}}=1-\varepsilon_{\mathrm{pt} / \mathrm{c}}-\varepsilon_{\mathrm{im}}
$$

244 where $M_{1 \mathrm{w}}\left(\mathrm{kg} \mathrm{mol}^{-1}\right)$ and $\rho_{\mathrm{lw}}\left(\mathrm{kg} \mathrm{m}^{-3}\right)$ are the molecular weight and density of 245 liquid water, $E W\left(\mathrm{~kg} \mathrm{~mol}{ }^{-1}\right)$ the equivalent weight of ionomer and $\lambda$ the 246 membrane water content.

\subsection{Three-dimensional multi-phase model}

249 The agglomerate sub-model developed in this study is incorporated into a 3D 250 multi-phase non-isothermal model. The conservation equations involved in this 251 model are summarized as below: 
252 Mass:

$$
\frac{\partial}{\partial t}\left(\varepsilon(1-s) \rho_{\mathrm{g}}\right)+\nabla \cdot\left(\rho_{\mathrm{g}} \vec{u}_{\mathrm{g}}\right)=S_{\mathrm{m}}
$$

253 Momentum:

$$
\frac{\partial}{\partial t}\left(\frac{\rho_{\mathrm{g}} \vec{u}_{\mathrm{g}}}{\varepsilon(1-s)}\right)+\nabla \cdot\left(\frac{\rho_{\mathrm{g}} \vec{u}_{\mathrm{g}} \vec{u}_{\mathrm{g}}}{\varepsilon^{2}(1-s)^{2}}\right)=-\nabla P_{\mathrm{g}}+
$$

$$
\mu_{\mathrm{g}} \nabla \cdot\left(\nabla\left(\frac{\vec{u}_{\mathrm{g}}}{\varepsilon(1-s)}\right)+\nabla\left(\frac{\vec{u}_{\mathrm{g}}^{\mathrm{T}}}{\varepsilon(1-s)}\right)\right)-\frac{2}{3} \mu_{\mathrm{g}} \nabla \cdot\left(\nabla\left(\frac{\vec{u}_{\mathrm{g}}}{\varepsilon(1-s)}\right)\right)+S_{\mathrm{u}}
$$

255 Species:

$$
\frac{\partial}{\partial t}\left(\varepsilon(1-s) \rho_{\mathrm{g}} Y_{\mathrm{i}}\right)+\nabla \cdot\left(\rho_{\mathrm{g}} \vec{u}_{\mathrm{g}} Y_{\mathrm{i}}\right)=\nabla \cdot\left(\rho_{\mathrm{g}} D_{\mathrm{i}}^{\mathrm{eff}} \nabla Y_{\mathrm{i}}\right)+S_{\mathrm{i}}
$$

256 Energy:

$$
\begin{aligned}
& \frac{\partial}{\partial t}\left(\varepsilon s \rho_{1 \mathrm{w}} C_{\mathrm{p}} T_{1 \mathrm{w}}+\varepsilon(1-s) \rho C_{\mathrm{g}} T\right)_{\mathrm{p}}+\mathrm{g},\left(\varepsilon s \rho \quad C \quad \vec{\psi}_{\mathrm{lw}} T_{\mathrm{p}}+\xi(1-s) \rho C \quad \vec{u} T\right) \\
& =\nabla \cdot\left(k^{\mathrm{eff}} \nabla T\right)+S_{\mathrm{T}}
\end{aligned}
$$

where $\rho_{\mathrm{g}}\left(\mathrm{kg} \mathrm{mol}^{-1}\right), \vec{u}_{\mathrm{g}}, \vec{u}_{\mathrm{lw}}\left(\mathrm{m} \mathrm{s}^{-1}\right), P_{\mathrm{g}}(\mathrm{Pa}), \mu_{\mathrm{g}}\left(\mathrm{kg} \mathrm{m}^{-1} \mathrm{~s}^{-1}\right), \varepsilon, s, Y_{\mathrm{i}}, D_{\mathrm{i}}^{\text {eff }}\left(\mathrm{m}^{2} \mathrm{~s}^{-1}\right), C_{\mathrm{p}, \mathrm{g}}$,

$259 C_{\mathrm{p}, \mathrm{lw}}\left(\mathrm{J} \mathrm{mol}^{-1} \mathrm{~K}^{-1}\right), T(\mathrm{~K})$ and $k^{\mathrm{eff}}\left(\mathrm{W} \mathrm{m}^{-1} \mathrm{~K}^{-1}\right)$ are the gas mixture density,

260 superficial velocity vector, pressure and dynamic viscosity of gas mixture, porosity

261 ("1" for channel), liquid water saturation, mass fraction and effective diffusion

262 coefficient of species "i" (i represents hydrogen, oxygen or water vapor), specific

263 heat capacity, temperature and effective thermal conductivity, respectively.

265 In channel, the liquid water is assumed to be in mist state [18] and thus the liquid 266 water saturation conservation equation [19] is solved, in which liquid water velocity $\left(\vec{u}_{1 \mathrm{w}}\right)$ equals to gas velocity $\left(\vec{u}_{\mathrm{g}}\right)$ :

$$
\frac{\partial}{\partial t}\left(\rho_{\mathrm{lw}} \varepsilon s\right)+\nabla \cdot\left(\rho_{\mathrm{lw}} \vec{u}_{\mathrm{lw}} s\right)=S_{\mathrm{lw}}
$$

269 And liquid pressure conservation equation is solved in the porous electrodes in order 
270 to consider the liquid water saturation jump at the interfaces:

$$
\frac{\partial}{\partial t}\left(\rho_{\mathrm{lw}} \varepsilon s\right)=\nabla \cdot\left(\rho_{\mathrm{lw}} \frac{K k_{\mathrm{lw}}}{\mu_{\mathrm{lw}}} \nabla P_{\mathrm{lw}}\right)+S_{\mathrm{lw}}
$$

272 where $K\left(\mathrm{~m}^{2}\right)$ and $k_{\mathrm{lw}}$ are the intrinsic permeability of porous media and relative

273 permeability of liquid water. Then the liquid water saturation can be obtained

274 through the Leverett-J function [20].

276 Other conservation equations concerning the electrochemical reaction are:

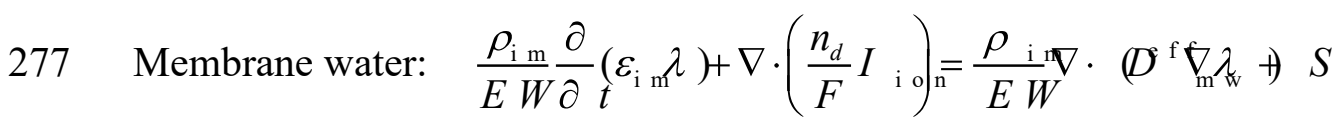

278 Electronic potential:

$$
0=\nabla \cdot\left(\kappa_{\text {ele }}^{\text {eff }} \nabla \varphi_{\text {ele }}\right)+S_{\text {ele }}
$$

279 Ionic potential:

$$
0=\nabla \cdot\left(\kappa_{\text {ion }}^{\text {eff }} \nabla \varphi_{\text {ion }}\right)+S_{\text {ion }}
$$

280 where $n_{d}, I_{\text {ion }}\left(\mathrm{A} \mathrm{m}^{-2}\right), D_{\mathrm{mw}}^{\text {eff }}\left(\mathrm{m}^{2} \mathrm{~s}^{-1}\right), \kappa_{\text {ele }}^{\text {eff }}$ and $\kappa_{\text {ion }}^{\text {eff }}\left(\mathrm{S} \mathrm{m}^{-1}\right)$ represent the

281 electro-osmotic drag (EOD) coefficient, the ionic current density, the effective

282 diffusion coefficient of membrane water, the effective electron and ion conductivity,

283 respectively. The source terms in electronic and ionic potential conservation

284 equations are calculated through the Butler-Volmer equations (B-V equations):

$$
\begin{gathered}
j_{\mathrm{a}}=i_{0, \mathrm{a}}^{\mathrm{ref}} A_{\mathrm{pt}} \theta_{\mathrm{T}, \mathrm{a}}\left(\frac{C_{\mathrm{H}_{2}}}{C_{\mathrm{H}_{2}}^{\mathrm{ref}}}\right)^{0.5}\left(\exp \left(\frac{2 F \alpha_{\mathrm{a}}}{R T} \eta_{\mathrm{a}}\right)-\exp \left(-\frac{2 F \alpha_{\mathrm{c}}}{R T} \eta_{\mathrm{a}}\right)\right) \\
j_{\mathrm{c}}=i_{0, \mathrm{c}}^{\mathrm{ref}} A_{\mathrm{pt}} \theta_{\mathrm{T}, \mathrm{c}}\left(\frac{C_{\mathrm{O}_{2}}^{\mathrm{pt}}}{C_{\mathrm{O}_{2}}^{\mathrm{ref}}}\right)\left(\exp \left(-\frac{4 F \alpha_{\mathrm{c}}}{R T} \eta_{\mathrm{c}}\right)-\exp \left(\frac{4 F \alpha_{\mathrm{a}}}{R T} \eta_{\mathrm{c}}\right)\right)
\end{gathered}
$$

$$
\theta_{\mathrm{T}, \mathrm{a}}=\exp \left(\frac{-1400(353.15-T)}{353.15 T}\right), \theta_{\mathrm{T}, \mathrm{c}}=\exp \left(\frac{-7900(353.15-T)}{353.15 T}\right)
$$


where $i_{0}^{\text {ref }}\left(\mathrm{A} \mathrm{m}{ }^{-2}\right), \theta_{\mathrm{T}}, C_{\mathrm{H}_{2}}^{\mathrm{ref}}, C_{\mathrm{O}_{2}}^{\mathrm{ref}}\left(\mathrm{mol} \mathrm{m}^{-3}\right), \alpha$ and $\eta(\mathrm{V})$ are the reference exchange

289 current density, the temperature correction coefficient, the reference molar

290 concentration of hydrogen and oxygen, the transfer coefficient and the overpotential,

291 respectively. According to Subramanian et al.'s work [21], excess oxygen around Pt

292 surface may have negative effect on electrochemical reaction under very low current

293 density. The Pt-oxide coverage-dependent correction coefficient fitted by Hao et al.

294 [13] is introduced to revise the cathode B-V equation. In addition, excess ionomer

coverage is also harmful to the catalyst activity. So another Pt-ionomer

coverage-dependent correction coefficient is fitted in this study based on

experimental data [14].

$$
j_{\mathrm{c}}=i_{0, \mathrm{c}}^{\mathrm{ref}} A_{\mathrm{pt}} \theta_{\mathrm{T}, \mathrm{c}} \theta_{\mathrm{pt} \text { im }}\left(1-\theta_{\mathrm{ptto}}\right)\left(\frac{C_{\mathrm{O}_{2}}^{\mathrm{pt}}}{C_{\mathrm{O}_{2}}^{\mathrm{ref}}}\right)\left(\exp \left(-\frac{4 F \alpha_{\mathrm{c}}}{R T} \eta_{\mathrm{c}}-\frac{\omega \theta_{\mathrm{pt} / \mathrm{o}}}{R T}\right)-\exp \left(\frac{4 F \alpha_{\mathrm{a}}}{R T} \eta_{\mathrm{c}}\right)\right)
$$

$$
\theta_{\mathrm{pt} / \mathrm{o}}=\frac{1}{1+e^{22.4(0.818-E)}}, \theta_{\mathrm{pt} / \mathrm{im}}=1-\exp \left[-30.6\left(\frac{\zeta_{\mathrm{pttc}}}{\zeta_{\mathrm{im} / \mathrm{c}}\left(1-\zeta_{\mathrm{pt} / \mathrm{c}}\right)}\right)^{2.6}\right]
$$

300 where $\omega\left(\mathrm{J} \mathrm{mol}^{-1}\right)$ is the energy parameter, $E(\mathrm{~V})$ the cathode potential vs.

301 Reversible Hydrogen Electrode (RHE), $\theta_{\mathrm{pt} / \mathrm{o}}$ the Pt-oxide coverage-dependent correction coefficient and $\theta_{\mathrm{pt} \text { im }}$ the Pt-ionomer coverage-dependent correction

303 coefficient. Combine Eq. (12), (13), (14), (15) and (35) together and oxygen local transport resistance can be taken into account:

$$
\frac{j_{\mathrm{c}}}{4 F A_{\text {im }}}=\frac{R T C_{\mathrm{O}_{2}}^{\mathrm{g}} / H_{\mathrm{O}_{2}}}{\frac{4 F A_{\text {im }} C_{\mathrm{O}_{2}}^{\text {ref }}}{k_{\text {ele }}}+R_{\mathrm{lw}}+\left(k_{1} \frac{A_{\text {im }}}{A_{\mathrm{pt}}}+1\right) R_{\mathrm{im}, \text { diffu }}+k_{2} R_{\mathrm{pt}}}
$$




$$
k_{\mathrm{ele}}=i_{0, \mathrm{c}}^{\text {ref }} A_{\mathrm{pt}} \theta_{\mathrm{T}, \mathrm{c}} \theta_{\mathrm{pttim}}\left(1-\theta_{\mathrm{pto}}\right)\left(\exp \left(-\frac{4 F \alpha_{\mathrm{c}}}{R T} \eta_{\mathrm{c}}-\frac{\omega \theta_{\mathrm{ptoo}}}{R T}\right)-\exp \left(\frac{4 F \alpha_{\mathrm{a}}}{R T} \eta_{\mathrm{c}}\right)\right)
$$

307 where the first term in the denominator of right side in Eq. (37) can be regarded as 308 another resistance term-electrochemical resistance $\left(R_{\text {ele }}, \mathrm{s} \mathrm{m}^{-1}\right)$ :

$$
R_{\text {ele }}=\frac{4 F A_{\text {im }} C_{\mathrm{O}_{2}}^{\text {ref }}}{k_{\text {ele }}}
$$

310 It should be noted that the relative magnitudes of the electrochemical resistance $\left(R_{\text {ele }}\right)$

311 against the local transport resistance $\left(R_{\text {local }}\right)$ indicates the control of electrochemical

312 factors or transport factors on the cathode CL reaction. With respect to the anode

313 side, B-V equation is corrected only by Henry's law at gas-ionomer interface due to

314 the good permeability of hydrogen and inapparent concentration loss compared with

315 the cathode side.

$$
j_{\mathrm{a}}=i_{0, \mathrm{a}}^{\text {ref }} A_{\mathrm{pt}} \theta_{\mathrm{T}, \mathrm{a}}\left(\frac{R T C_{\mathrm{H}_{2}}^{\mathrm{g}}}{H_{\mathrm{H}_{2}} C_{\mathrm{H}_{2}}^{\text {ref }}}\right)^{0.5}\left(\exp \left(\frac{2 F \alpha_{\mathrm{a}}}{R T} \eta_{\mathrm{a}}\right)-\exp \left(-\frac{2 F \alpha_{\mathrm{c}}}{R T} \eta_{\mathrm{a}}\right)\right)
$$

317 where $H_{\mathrm{H}_{2}}\left(\mathrm{~Pa} \mathrm{~m}^{3} \mathrm{~mol}^{-1}\right)$ is the Henry's constant of hydrogen in ionomer.

319 The mass flow rate and constant pressure are specified at inlet and outlet boundaries,

320 respectively:

$$
\begin{gathered}
\dot{m}_{\mathrm{a}}=\frac{j_{\mathrm{a}} \xi_{\mathrm{a}} A_{\mathrm{act}}^{\mathrm{a}} \rho_{\mathrm{g}}^{\mathrm{a}}}{2 F C_{\mathrm{H}_{2}}}, C_{\mathrm{H}_{2}}=\frac{P_{\mathrm{g}, \text { out }}^{\mathrm{a}}+\Delta P_{\mathrm{g}}^{\mathrm{a}}-R H_{\mathrm{a}} P_{\mathrm{sat}}}{R T} \\
\dot{m}_{\mathrm{c}}=\frac{j_{\mathrm{c}} \xi_{\mathrm{c}} A_{\text {act }}^{\mathrm{c}} \rho_{\mathrm{g}}^{\mathrm{c}}}{4 F C_{\mathrm{O}_{2}}}, C_{\mathrm{O}_{2}}=\frac{0.21\left(P_{\mathrm{g}, \text { out }}^{c}+\Delta P_{\mathrm{g}}^{c}-R H_{\mathrm{c}} P_{\text {sat }}\right)}{R T}
\end{gathered}
$$

323 where $\xi, A_{\text {act }}\left(\mathrm{m}^{2}\right), R H$ and $P_{\text {sat }}(\mathrm{Pa})$ are stoichiometric ratio, active area, relative 
324 humidity and water saturation pressure, respectively. And boundary conditions

325 (B.C.s) of electronic potential are defined with the total overpotential to anode side

326 and zero potential to cathode side:

$$
\varphi_{\mathrm{ele}}^{\mathrm{a}}=E_{\mathrm{rev}}-V_{\mathrm{out}}, \varphi_{\mathrm{ele}}^{\mathrm{c}}=0
$$

328 where $E_{\text {rev }}(\mathrm{V})$ is the reversible thermodynamic voltage and $V_{\text {out }}(\mathrm{V})$ the output

329 voltage. Additionally, constant surface temperature is specified to all the surrounding

330 walls. Physical and transport parameters are listed in Table 1 and more detailed

331 information can be found in Ref. [22]. And Table 2 gives the source terms of the

332 above conservation equations.

\section{3. Results and discussion}

335 A typical single channel computational domain including bipolar plates (BPs), flow

336 channels (CHs), gas diffusion layers (GDLs), micro-porous layer (MPLs), CLs and

337 proton exchange membrane (PEM) is shown in Fig. 2. This study is conducted with

338 the help of the commercial computational fluid dynamics (CFD) software FLUENT,

339 and the user-defined function (UDF) is used. Grid independence is tested by

340 comparing the calculated current density at the same output voltage using different

341 mesh density. The results are shown in Table 3 and mesh 4 is adopted in this study.

\subsection{Model validation}

344 For the 3D multi-phase model of PEM fuel cell, the polarization curve and ohmic 
345 loss have been validated in previous work [23]. In this study, the simulated

346 polarization curves are further compared with experimental data under different

347 cathode Pt loadings without carbon dilution (from 0.3 to $0.025 \mathrm{mg} \mathrm{cm}^{-2}$ ). Fig. 3

348 shows the comparison and the consistency is acceptable. The maximum current

349 density deviation doesn't exceed $0.1 \mathrm{~A} \mathrm{~cm}-2$ and the corresponding maximum

350 validation error (\%) is smaller than $15 \%$ for single data point. In addition, Fig. 4

351 compares simulated polarization curves using different CL models under $0.2 \mathrm{mg}$

$352 \mathrm{~cm}^{-2}$ cathode $\mathrm{Pt}$ loading. Obviously, homogeneous model overestimate cell

353 performance markedly. With the solution methods of Sun et al. [7], traditional

354 large-size agglomerate model (agglomerate diameter $380 \mathrm{~nm}$, ionomer film thickness

$35520 \mathrm{~nm}$ ) gains similar results with improved small-size agglomerate model developed

356 by this study (agglomerate diameter $50 \mathrm{~nm}$, ionomer film thickness $8 \mathrm{~nm}$ ). This also

357 supports the conclusion of Greszler et al. [9] and proves the validity of current

358 model. Moreover, Fig. 5 gives the results of oxygen local transport resistance and

359 similar preceding work in the open literature is also exhibited $[24,25] . \quad R_{\text {local }}$ by this

360 study falls into the range of existing studies and matches the data of Owejan et al.

361 [14] reasonably. In this validation, the undetermined parameter $\left(k_{1}\right)$ in Eq. (5) is

362 assigned as 0.15 . Design and model parameters of validation cases are listed in Table

3634 and the 5 different CL formulations can be found in Table 5. 
In Fig. 6 , the total local transport resistance $\left(R_{\text {local }}\right)$ and two partial resistances $\left(R_{\mathrm{im}}\right.$,

$\left.367 R_{\mathrm{pt}}^{*}\right)$ under different Pt loadings are shown. The transport resistance caused by liquid

368 water $\left(R_{\mathrm{lw}}\right)$ is neglected because of its much smaller value (two orders of magnitude

369 smaller than the others). Opposite variation trends of the ionomer coverage

370 resistance and the $\mathrm{Pt} /$ carbon agglomeration resistance can be clearly seen as $\mathrm{Pt}$

371 loading $(\mathrm{Pt} / \mathrm{C}$ percentage) changes. For all the $5 \mathrm{CL}$ formulations, $\mathrm{I} / \mathrm{C}$ ratio $(0.95)$ is

372 constant but $\mathrm{Pt} / \mathrm{C}$ percentage is different so that the different $\mathrm{Pt}$ loading represents

373 different $\mathrm{Pt} / \mathrm{C}$ percentage, i.e. different Pt particle density on carbon support. Higher

374 Pt loading results in inevitable deposition of $\mathrm{Pt}$ particles and the correction

375 coefficient $\left(k_{2}\right)$ gains a larger value. Contrarily, oxygen may go through a longer

376 and rougher "road" in ionomer film under lower Pt/C percentage ( $R_{\text {im }}$ rises). When

377 Pt loading is lower than $0.1 \mathrm{mg} \mathrm{cm}^{-2}$, the total local transport resistance sharply goes

378 up due to the much larger value of the specific area ratio $\left(A_{\mathrm{im}} / A_{\mathrm{pt}}\right)$. Although the

379 agglomeration effect decreases as less Pt particles deposit into primary pores, it

380 cannot offset the growth of the ionomer resistance. In other words, a relatively

381 heavier ionomer coating causes severe oxygen transport loss under extreme low $\mathrm{Pt}$

382 loadings.

384 Instead, a slight increase of the total resistance is observed when Pt loading changes

385 from 0.2 to $0.3 \mathrm{mg} \mathrm{cm}$. The negative effect of agglomeration and deposition is

386 more obvious because the ionomer resistance changes indistinctively. The finding 
seems to be only supported by Owejan et al.'s [14] experimental data, not by others

388 (e.g. Sakai et al. [24]). But it should be noted that, during Owejan et al.'s

389 experiments, the CL thickness were kept unchanged within the capability of coating

390 method, which is different from other studies. The calculated CL porosities almost

391 hold a constant $(\sim 0.5)$ because the carbon and ionomer loadings basically maintain

392 the same. In this case, excess Pt loading may also be detrimental to oxygen transport

393 due to higher Pt particle density. Generally speaking, the compositional parameters

394 used to prepare the catalyst layer ink influence the structural topology of CL (e.g. Pt

395 particle density) and hence affect the oxygen local transport characteristics. Based

396 on the above analysis, a possible way to mitigate the negative effect on oxygen

397 transport can be concluded. Through the optimization of coating method and

398 electrode design, it's promising to avoid the catalyst being completely or heavily

399 covered by ionomer and disperse the Pt particles more evenly on carbon support.

400

4013.3 Transport dominance parameter

402 The electrochemical resistance ( $R_{\text {ele }}$ ) expressed by Eq. (39) is a collection of

403 electrochemical parameters related to oxygen reduction reaction (ORR). It has the

404 same unit with transport resistance $\left(\mathrm{s} \mathrm{m}^{-1}\right)$ and represents the last step before oxygen

405 is consumed. By comparing the local transport resistance with the electrochemical

406 resistance, a transport dominance parameter ( $l$ ) can be derived: 


$$
\imath=\frac{R_{\text {local }}}{R_{\text {ele }}+R_{\text {local }}} \times 100 \%
$$

408 Fig. 7 shows the polarization curves and the corresponding transport dominance

409 curves with more complete data under three cathode Pt loadings $(0.2,0.1,0.05 \mathrm{mg}$

$410 \mathrm{~cm}^{-2}$ ). The concentration loss region is highlighted. As seen from Fig. 7, the

411 electrochemical factors dominate the cathode ORR under low and middle current

412 densities as the value of transport dominance is fairly small. However, a turning

413 appears as current density continues to increase indicating the transport factors begin

414 to play a major role. After the turning, the transport dominance increases

415 dramatically near the limiting current density $\left(3 \mathrm{~A} \mathrm{~cm}^{-2}\right)$ which means the

416 electrochemical reaction is suffering severe concentration loss. Therefore, the

417 transport dominance parameter can be used to judge whether the oxygen starvation

418 shows up under a certain output condition. According to the turning range in Fig. 7,

419 a value greater than $10 \%$ can represent a symbol of obvious concentration loss.

\subsection{Fine channel geometry design}

422 In view of the hard transport process of oxygen as explained above, besides the

423 optimization of CL preparation, the cathode flow field design is also of great

424 significance in providing sufficient oxygen supply. The common flow fields usually consist of channel and rib. Limited by the machining precision, the wide rib (mostly 

the rib/channel design such as air-guide plate and converging/diverging channel [26, 27]. Others jumped out of the "channel and rib" pattern such as $3 \mathrm{D}$ fine mesh flow

430 field and metal foam flow field [28, 29]. These novel structures successfully avoid 431 the bad effect of rib and greatly increase fuel cell performance.

433 In fact, with the fast development of manufacturing technology, we can imagine that 434 the widths of channel and rib may be reduced to extremely small (about $0.1 \mathrm{~mm}$ ).

435 Then the effects of rib are likely to be negligible. As a consequence, using the model 436 developed in this study, 8 cases are set up regarding PEM fuel cell with fine flow 437 channel and rib, which are shown in Table 6. Case 1-6 give different groups of fine 438 channel widths and channel heights considering the $0.1-0.2 \mathrm{~mm}$ width range. The 439 metal foam channel (without real structure) is considered in case 7 and case 8 uses 440 traditional channel width as comparison. For these 8 cases, some operation 441 conditions are reset to better agree with technology actuality of the state of the art 442 fuel cell vehicles, including relative humidity (anode $0.2 \&$ cathode 0.3 ) and 443 stoichiometry ratio (anode $1.2 \&$ cathode 2.0 ). In addition, cathode Pt loading uses 444 the $0.2 \mathrm{mg} \mathrm{cm}^{-2}$ formulation in Table 5 and the anode reference exchange current 445 density is adjusted within reasonable range. 


$$
W_{\text {pump }}=\Delta P \bar{u}_{\text {in }} A_{\text {in }} / A_{\text {act }} / \eta
$$

where $\Delta P(\mathrm{~Pa}), \bar{u}_{\text {in }}\left(\mathrm{m} \mathrm{s}^{-1}\right), A_{\text {in }}\left(\mathrm{m}^{2}\right), A_{\text {act }}\left(\mathrm{m}^{2}\right), \eta$ are pressure drop, average inlet

a result, case 3,5 gives the best net power density at intermediate output voltage. In addition, the pumping loss and transport dominance at $0.3 \mathrm{~V}$ output voltage are

large value of transport dominance (about 12\%), indicating that concentration loss is

459 obvious, which can also be seen in Fig. 8. It's worth noting that case 7 has nearly the

460 same pumping loss as case 5 but much lower transport dominance possibly because

461 of the homogeneous porous media hypothesis. Considering better aspect ratio of

462 channel cross section, 0.2-width/0.6-height channel geometry (case 5) stands out as

463 the best among the fine channel geometry designs. And the transport dominance at

$464 \quad 0.3 \mathrm{~V}$ is still lower than $10 \%$.

466 Additionally, the oxygen molar concentration distribution in the middle plane of

467 cathode CL and current density distribution in the middle plane of membrane (case 5,

4687 and 8, $2.0 \mathrm{~A} \mathrm{~cm}^{-2}$ ) are shown in Fig. 10, respectively. The metal foam channel 
469 (case 7) gives the most uniform oxygen distribution at in-plane direction and fine 470 channel geometry case (case 5) also performs better than traditional channel 471 geometry case (case 8). As for current density distribution, both case 5 and 7 are 472 much more uniform than case 8 . It should be noted that the output voltage of case 5 $473(0.6 \mathrm{~V})$ is a little higher than that of case $7(0.58 \mathrm{~V})$. This agree with the conclusion of 474 Kumar et al. [30] that the rib-channel structure can perform better than the metal 475 foam under the same permeability. Using the Hagen-Poiseuille equation [31], the 476 equivalent permeability of normal flow channel can be obtained through the 477 hydraulic diameter. The permeability of the fine channel geometry (case 5) is 478 calculated to be $3.2 \mathrm{e}-9\left(\mathrm{~m}^{2}\right)$ which is close to the metal foam permeability adopted 479 in this study $\left(1.0 \mathrm{e}-9 \mathrm{~m}^{2}\right)$. Hence, fine channel geometry has the competence to 480 further improve the PEM fuel cell performance.

\section{Conclusion}

483 In this study, an improved agglomerate sub-model of catalyst layer (CL) in proton 484 exchange membrane (PEM) fuel cell is developed with the consideration of 485 reasonable agglomerate size and Pt loading effect on oxygen transport. The oxygen 486 local transport characteristics before arriving at the catalyst surface is clarified with 487 detail by analyzing the composition of transport resistance at single agglomerate 488 scale. The local transport resistance is separated into three individual resistance 489 terms, namely the liquid water resistance, ionomer coverage resistance and 
$\mathrm{Pt} /$ carbon agglomeration resistance. The Pt particle dispersion, the dissolution effect at gas-ionomer interface and Knudsen diffusion in primary pores are take into account. The final expression of local transport resistance (Eq. (12)) is related to catalyst layer formulation parameters, including Pt loading, Pt weight percentage of $\mathrm{Pt} /$ carbon catalyst $(\mathrm{Pt} / \mathrm{C}$ percentage) and mass ratio of ionomer to carbon ( $\mathrm{I} / \mathrm{C}$ ratio), which agrees with conclusions of former studies. In addition, by separating the electrochemical part and transport part in cathode B-V equation, a transport dominance parameter is derived. It can be used to evaluate the control of transport factors on reaction rate compared with the influence of electrochemical factors. According to the turning range, a value lager than $10 \%$ can be seen as a sign of local oxygen starvation. The sub-model is further coupled into a three-dimensional multi-phase PEM fuel cell model. An optimization research of fine channel geometry with extremely small channel (rib) width is conducted. Main conclusions are summarized as below:

- The local transport resistance mainly come from the ionomer coverage and $\mathrm{Pt} /$ carbon agglomeration and they manifest opposite variation trends. Under extreme low Pt loading $\left(<0.1 \mathrm{mg} \mathrm{cm}^{-2}\right)$, the ionomer resistance increases dramatically and become dominant possibly due to the relatively heavier ionomer coating. The transport pathway of oxygen flux should be much more complicated in this case.

- On the other hand, the agglomeration resistance is more evidently and causes a 

$\mathrm{cm}^{-2}$. The reason is that $\mathrm{Pt}$ particles get more concentrated so that a larger proportion of them is likely to deposit into primary pores. Consequently, excess

520 - With the expectation of manufacturing technology, fine channel geometry is

521 found to greatly improve the uniformity of gas distribution and increase fuel cell 522 performance effectively. The optimized channel width and height are 0.2 and $523 \quad 0.6 \mathrm{~mm}$, respectively, which gives the highest net power density. And the 524 transport dominance at $0.3 \mathrm{~V}$ output voltage is still acceptable $(<10 \%)$. As a 525 result, the fine channel and rib can serve as another competitive choice to 526 improve the oxygen distribution and sufficiency regarding the flow field design

528 The large-scale commercialization of PEM fuel cell is urgently needed as a more 529 clean and efficient energy conversion device. The analysis of the Pt loading effect on 530 oxygen transport can help understand the underlying transport phenomena inside 531 PEM fuel cell and fine channel geometry design may provide a potential idea to the 
R\&D. Also, the current model still fails to reflect the real microscopic transport mechanism in ionomer due to lack of knowledge. There exists fitting empirical coefficients in this study, which may be short of universality. And the Pt loading effect on the coupled electrochemical kinetics and transport phenomena needs further investigation, which also remains a future task in follow-up studies.

\section{Acknowledgements}

This work is supported by the National Key Research and Development Program of China (Grant No. 2017YFB0102703), the National Natural Science Foundation of China for International Cooperation and Exchange (Newton Advanced Fellowship) (Grant No. 51861130359, NAF\R1\180146), and the National Natural Science Foundation of Tianjin (China) for Distinguished Young Scholars (Grant No. 18JCJQJC46700)

\section{References}

[1] Wang Y, Chen K, Mishler J, Cho S, Adroher X. A review of polymer electrolyte membrane fuel cells: Technology, applications, and needs on fundamental research. Applied Energy, 88 (4) (2011), 981-1007.

[2] 2015 DOE Hydrogen and Fuel Cells Program Review: Fuel Cell Vehicle and Bus Cost Analysis. Department of Energy (2015).

[3] Berning T, Djilali N. Three-dimensional computational analysis of transport 
553 phenomena in a PEM fuel cell-a parametric study. Journal of Power Sources, $554 \quad 124(2)(2003), 440-452$.

555 [4] Lum K, Mcguirk J. Three-dimensional model of a complete polymer electrolyte 556 membrane fuel cell-model formulation, validation and parametric studies. 557 Journal of Power Sources, 143 (1-2) (2005), 103-124.

558 [5] Ridge S, White R. Oxygen Reduction in a Proton Exchange Membrane Test 559 Cell. Journal of The Electrochemical Society, 136 (7) (1989), 1902-1909.

560 [6] Siegel N, Ellis M, Nelson D, Spakovsky M. Single domain PEMFC model 561 based on agglomerate catalyst geometry. Journal of Power Sources, 2003, 562 115(1):81-89.

563 [7] Sun W, Peppley B, Karan K. An improved two-dimensional agglomerate 564 cathode model to study the influence of catalyst layer structural parameters. $565 \quad$ Electrochimica Acta, 50 (16-17) (2005), 3359-3374.

566 [8] Sakai K, Sato K, Mashio T, Ohma A. Analysis of Reactant Gas Transport in 567 Catalyst Layers; Effect of Pt-loadings. Journal of The Electrochemical Society, 568

569 [9] Greszler T, Caulk D, Sinha P. The Impact of Platinum Loading on Oxygen 570 Transport Resistance. Journal of The Electrochemical Society, 159 (12) (2012), $571 \quad$ F831-F840.

572 [10] Secanell M, Karan K, Suleman A, Djilali N. Multi-variable optimization of 573 PEMFC cathodes using an agglomerate model. Electrochimica Acta, 52 (22) 
575 [11]Kudo K, Suzuki T, Morimoto Y. Analysis of Oxygen Dissolution Rate from Gas 576 Phase into Nafion Surface and Development of an Agglomerate Model. Journal of The Electrochemical Society, 33 (1) (2010), 1495-1502.

[12] Suzuki T, Kudo K, Morimoto Y. Model for investigation of oxygen transport limitation in a polymer electrolyte fuel cell. Journal of Power Sources, 222 (2) (2013), 379-389.

581 [13]Hao L, Moriyama K, Gu W, Wang C Y. Modeling and Experimental Validation 582 of Pt Loading and Electrode Composition Effects in PEM Fuel Cells. Journal of The Electrochemical Society, 162 (8) (2015), F854-F867.

584 [14] Owejan J P, Owejan J E, Gu W. Impact of Platinum Loading and Catalyst Layer 585 Structure on PEMFC Performance. Journal of The Electrochemical Society, 160

587 [15]Chen L, Zhang R, He P, Kang Q, He Y L, Tao W Q. Nanoscale simulation of 588 local gas transport in catalyst layers of proton exchange membrane fuel cells. Journal of Power Sources, 400 (2018), 114-125.

590 [16] Sina S, Stumper J, Majid B. Direct measurement and modeling relative gas 591 diffusivity of PEMFC catalyst layers: The effect of ionomer to carbon ratio, 592 operating temperature, porosity, and pore size distribution. International Journal $593 \quad$ of Hydrogen Energy, 43 (2018), 16704-16718.

594 [17] Sakthivel M, Drillet J. An extensive study about influence of the carbon support 
597 [18]Zhang G, Jiao K. Three-dimensional multi-phase simulation of PEMFC at high current density utilizing Eulerian-Eulerian model and two-fluid model. Energy Conversion and Management, 176 (15) (2018), 409-421.

600 [19]Ye Q, Nguyen T. Three-Dimensional Simulation of Liquid Water Distribution in 601 a PEMFC with Experimentally Measured Capillary Functions. Journal of The 602 Electrochemical Society, 154 (12) (2007), B1242.

603 [20]Jiao K, Li X. Water transport in polymer electrolyte membrane fuel cells. 604 Progress in energy and combustion Science, 37 (3) (2011), 221-291.

605 [21] Subramanian N, Greszler T, Zhang J, Gu W, Makharia R. Pt-oxide 606 coverage-dependent oxygen reduction reaction (ORR) kinetics. Journal of The Electrochemical Society, 159 (5) (2012), B531-B540.

608 [22]Zhang G, Xie B, Bao Z, Niu Z, Jiao K. Multi-phase simulation of proton 609 exchange membrane fuel cell with 3D fine mesh flow field. International $610 \quad$ Journal of Energy research, 42 (15) (2018), 4697-4709.

611 [23]Zhang G, Fan L, Sun J, Jiao K. A 3D model of PEMFC considering detailed 612 multiphase flow and anisotropic transport properties. International Journal of $613 \quad$ Heat and Mass Transfer, 115 (2017), 714-724.

614 [24] Sakai K, Sato K, Mashino T, Ohma A, Yamaguchi K, Shinohara K. Analysis of 615 reactant gas transport in catalyst layers; effect of Pt-loadings. ECS Transactions, 
617 [25] Ono Y, Ohma A, Shinohara K, Fushinobu K. Influence of equivalent weight of 618 ionomer on local oxygen transport resistance in cathode catalyst layers. Journal of The Electrochemical Society, 160 (8) (2013), F779-F787.

620 [26]Fan L, Niu Z, Zhang G, Jiao K. Optimization design of the cathode flow 621 channel for proton exchange membrane fuel cells. Energy Conversion and Management, 171 (2018), 1813-1821.

[27]Zehtabiyan N, Arefian A, Kermani M J, Noughabi A K, Abdollahzadeh M. Effect of flow field with converging and diverging channels on proton exchange membrane fuel cell performance. Energy Conversion and Management, 152 (2017), 31-44.

627 [28] Yoshida T, Kojima K. Toyota MIRAI fuel cell vehicle and progress toward a future hydrogen society. Interface magazine, 24 (2) (2015), 45-49.

629 [29]Carton J. Representative model and flow characteristics of open pore cellular 630 foam and potential use in proton exchange membrane fuel cells. International 631 Journal of Hydrogen Energy, 40 (16) (2015), 5726-5738.

632 [30]Kumar A, Reddy R. Modeling of polymer membrane fuel cell with metal foam 633 in the flow-field of the bipolar/end plates. Journal of Power Sources, 114 (2003), 634 $54-62$.

635 [31]Wang Y, Basu S, Wang C Y. Modeling two-phase flow in PEM fuel cell 636 channels. Journal of Power Sources, 179 (2008), 603-617. 


\section{Figure and table captions}

639 Fig. 1. (a) SEM image of CL showing the secondary and primary pores [16]; (b)

640 TEM image of CL sample; (c) Schematic of single agglomerate and the three parts

641 of oxygen local transport resistance.

642 Fig. 2 Computational domain and mesh.

643 Fig. 3. Comparison of polarization curves between simulation results of this study

644 and experimental data under different cathode Pt loadings [14].

645 Fig. 4. Comparison of simulated polarization curves using homogeneous model, 646 traditional large-size agglomerate model (agglomerate diameter 380nm, ionomer 647 film thickness 20nm) and improved small-size agglomerate model (agglomerate 648 diameter 50nm, ionomer film thickness $8 \mathrm{~nm}$ ) under $0.2 \mathrm{mg} \mathrm{cm}-2$ cathode Pt loading.

649 Fig. 5. Comparison of local transport resistance between simulation results of this 650 study and other similar experimental results from the literature under different 651 cathode Pt loadings [14, 24, 25].

652 Fig. 6. The simulated total local transport resistance and two partial resistances 653 under different cathode Pt loadings.

654 Fig. 7. Polarization curves and corresponding transport dominance curves under 0.2 , $6550.1,0.05 \mathrm{mg} \mathrm{cm}-2$ cathode Pt loadings.

656 Fig. 8. Polarization curves and net power density of the 8 cases.

657 Fig. 9. Pumping loss and transport dominance of the 8 cases at $0.3 \mathrm{~V}$ output voltage. 
658 Fig. 10. Comparisons of (a) oxygen molar concentration distribution in the middle 659 plane of cathode CL; (b) current density distribution in the middle plane of 660 membrane among case 5, 7 and 8. ("MF" stands for metal foam)

661

662 Table 1. Physical and transport parameters.

663 Table 2. Source terms.

664 Table 3. Grid independence test results.

665 Table 4. Design and model parameters of the validation cases.

666 Table 5. Catalyst layer formulations of the 5 cathode Pt loadings [14].

667 Table 6. Design parameters of the 8 different channel geometry cases. 